Fermilab Accumulator Magnets Vacuum Chamber Heating System J.A. Satti and G.N. Lee 


\title{
Fermilab accumulator magnets vacuum chamber heating system
}

\author{
J. A. Satti and G. N. Lee \\ Fermi National Accelerator Laboratory, Batavia, Illinois 60510
}

(Received 22 October 1984; accepted 4 December 1984)

The Fermi National Accelerator Laboratory (Fermilab) is building an accumulator ring to store antiprotons for high energy physics proton-antiproton collisions in the Tevatron accelerator. The accumulator ring, approximately $474 \mathrm{~m}$ in circumference, consists of many quadrupole and dipole magnets connected with stainless steel vacuum chambers for beam circulation. The vacuum pressure required is in the low $10^{-10}$ Torr range. To reach this pressure, the vacuum chambers are baked at $300^{\circ} \mathrm{C}$ each time they have been opened to atmospheric pressure. The critical problem is to bake the chambers in the magnets at high temperature without overheating the laminated magnets. Some of the magnets are $5 \mathrm{~m}$ long with very restrictive space for the heaters and insulation. An average space of only $7.5 \mathrm{~mm}$ around the chambers is available. In this space a heating system has been designed and tested to heat the chamber to $300^{\circ} \mathrm{C}$ and allow a maximum temperature of $65^{\circ} \mathrm{C}$ next to the magnet components. This was accomplished by using a heating blanket completely covered with a water cooled copper heat sink jacket to protect the magnet from the high temperatures. The design of a final selected heating blankett is discussed. A prototype test results are given with comparison of calculated and measured temperature distribution.

\section{INTRODUCTION}

The accumulator is a high class storage ring designed to accept the injection of antiprotons every few seconds. The antiprotons traveling at $99.5 \%$ of the speed of light are accumulated over a period of several hours. Ultrahigh vacuum is required to minimize interaction of the circulating beam with the outgassed molecules of the chamber wall. A nominal pressure of $3 \times 10^{-10}$ Torr is required in the beam tubes to avoid beam intensity loss from excessive beam-gas collision. This pressure can be met with a combination of sublimation and sputter ion pumps, and with well conditioned chambers to reduce the rate of gas desorption. Each chamber section is first vacuum baked at $900^{\circ} \mathrm{C}$ for $2 \mathrm{~h}$ after the pressure is below $10^{-3}$ Torr. Thereafter the chambers are maintained clean. The in place conditioning is bakeout at temperature of $300^{\circ} \mathrm{C}$ for periods ranging from hours to several days depending on the conditions.

The main magnet system consists of 30 dipoles and 84 quadrupoles. Each magnet has its specially shaped tube

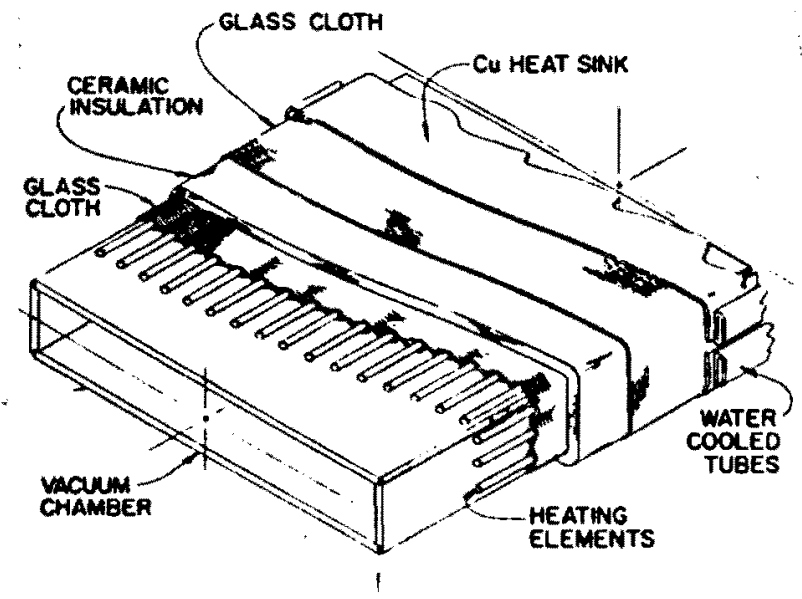

Fic. 1. Aakeout components. chamber for beam space efficiency. The space between the vacuum chamber and the magnet pole tip is minimized to reduce power consumption for the required magnetic field. With an average space of only $7.5 \mathrm{~mm}$, a $300^{\circ} \mathrm{C}$ bakeout system has been built with protection to the surrounding magnet.

\section{GENERAL DESCRIPTION OF THE BAKEOUT SYSTEM}

The bakeout system consists of a heating blanket comprised of heating elements incorporated in a glass fiber cloth carrier, a layer of ceramic fiber thermal insulation, and an outer surface glass fiber cloth. The blanket is wrapped around the stainless steel vacuum chamber, then covered with a copper sheet heat sink cooled by water. Figure 1 shows a pictorial view of the basic bakeout components in the dipole magnet and Figs. $2-4$ show the different cross sections of the vacuum chambers.

The heating blankets were made to specification' by ISOPAD Ltd. This general description summarizes the specification. The heating elements are woven into the glass

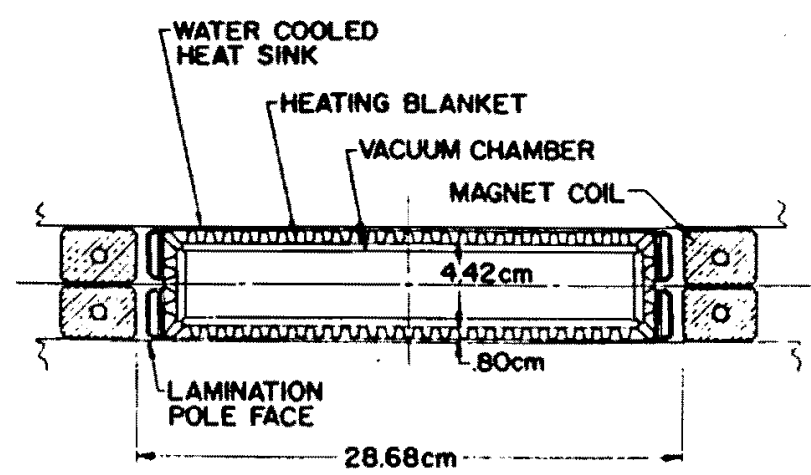

FiG. 2. Dipole bakeout system. :- 


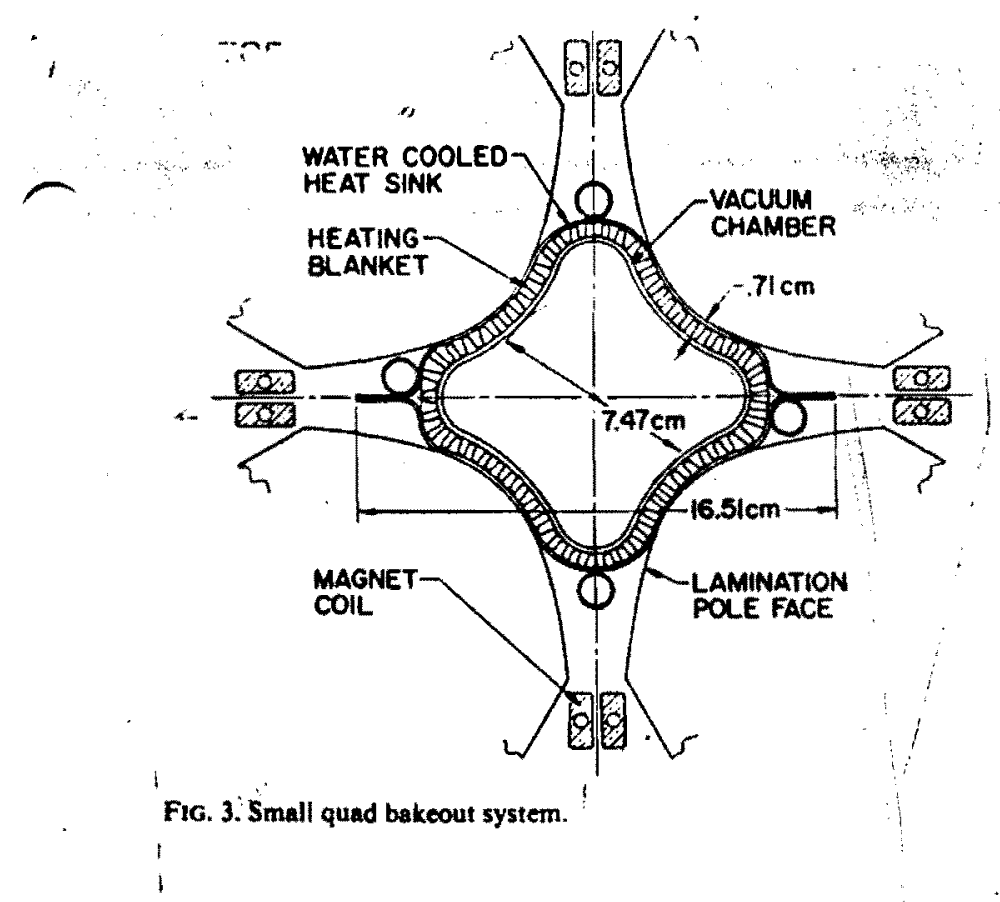

cloth next to the chambers. The blanket, tightly compressed between the tube and the copper heat sink, provides efficient heat transfer from the elements to the chamber surface. The elements are made of nonmagnetic nickel/chrome alloy and are insulated with high temperature materials. The elements, woven into the blanket, are laid longitudinal with the chambers. The ends are crimped to cold leads of multistranded copper/nickel wires. The connections incorporate a strain relief feature to minimize forces on the heating element/lead joint. On the large dipole magnets, dual circuits are installed in the blanket; so that during normal operation every other set of wires is powered. The heating elements cover the maximum possible chamber surface area. This provides a homogeneous temperature distribution. The elements are designed to give an average power of $3.9 \mathrm{~kW} / \mathrm{m}^{2}$ with $208 \mathrm{~V}$ operation.

The thermal insulation is a ceramic fiber blanket with a thermal conductivity of $0.08 \mathrm{~W} / \mathrm{m}^{\circ} \mathrm{C}$ at $300^{\circ} \mathrm{C}$. The material is attached to the carrier cloth in order not to be displaced when handling the blanket. The outer surface of the heating blanket is a glass cloth. Along the length of the vacuum

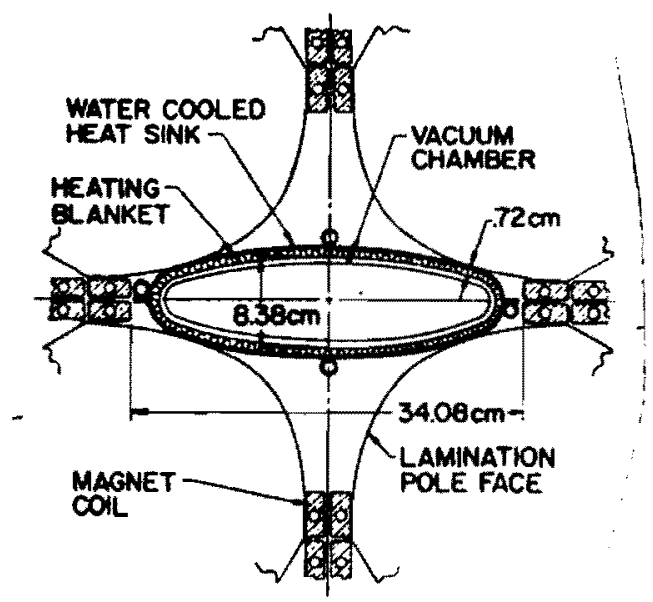

FiG. 4. Large quad bakeout system.

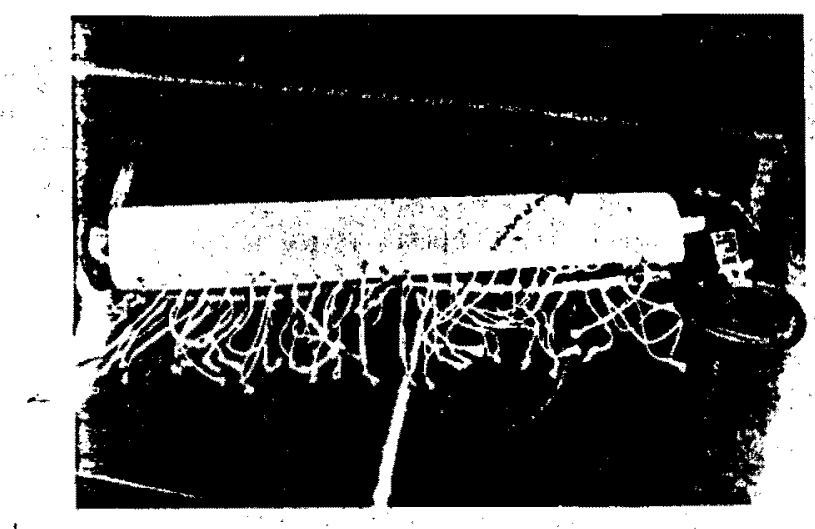

FiG. S. Smail quad heating blanket.

chamber, the blanket is tied together with laces sewn every 5 $\mathrm{cm}$. Figure 5 shows a heating blanket wrapped around a vacuum chamber of a sirhall quadrupole magnet.

The finished blanket is baked at the manufacturing plant at $305^{\circ} \mathrm{C}$ using all of the heating elements. This removes any sizing or finishes used in the manufacturing of the materials. After baking, the elements are tested to withstand a $1000 \mathrm{~V}$ ac between heating elements and the surfuce of the chamber.

A copper sheet $0.79 \mathrm{~mm}$ thick is formed to cover the blanket. This serves as a temperature shield between the blanket and the magnet steel laminations. Copper tubes are silver brazed to the shield. These tubes are connected in series with the low conductivity water (LCW) used to cool the magnet coils. Most of the heat used in the bakeout is dissipated into the water. The remaining heat gets absorbed into the magnet and eventually into the air in the tunnel. The shield keeps the temperature of the pole tip laminations below $80^{\circ} \mathrm{C}$ which is the critical value of the epoxy holding the laminations together at the ends.

Control and regulation of the temperature of the vacuum chambers are done by type $E$ thermocouple probes attached on the outside surface of the chambers. Type $E$ thermocouples were chosen because they are nonmagnetic. Each chamber has several spare thermocouples depending on the length of the chamber. The power is regulated by opening or closing a relay in the heating circuit. The rate of temperature increase $\left(-50^{\circ} \mathrm{C} / \mathrm{h}\right)$ is controlled by a microprocessor. A typical bakeout of $300^{\circ} \mathrm{C}$ lasts for about $20 \mathrm{~h}$.

\section{HEAT TRANSFER CALCULATION}

Steady one-dimensional heat transfer analysis was used to calculate the temperatures and the heat required for the bakcout systen. Figure 6 shows the thermal circuit for the heat flow from the vacuum chamber to the cooling water and the air.

To solve the temperatures of the copper shield and the center of the steel lamination, two heat flow equations were used:

$$
\begin{aligned}
& q_{v-1}=q_{1-2}+q_{1-1}, \\
& q_{1-3}=q_{3-4}+q_{3-5} .
\end{aligned}
$$

From Eq. (1), the heat flow from the $300^{\circ} \mathrm{C}$ vacuum chamber to the copper shield is equal to the sum of the heat flows of 


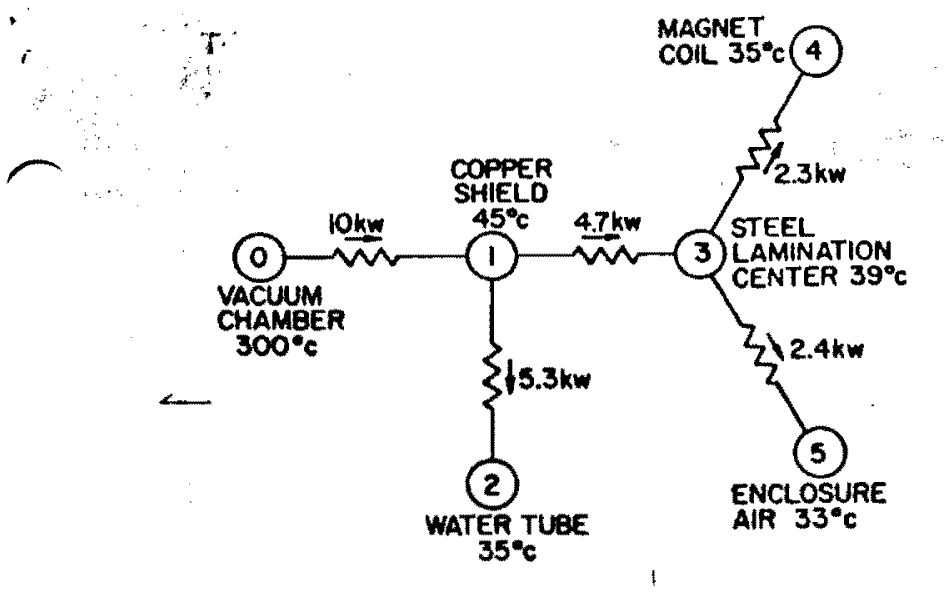

FuG. 6. Thermal circuit of large dipole.

$$
\text { L : vneNT }
$$

the copper shield to the water tube and the steel lamination. The heat flowing from the center of the steel lamination to the magnet coil and the enclosure air is given by Eq. (2).

The same basic equations were used for the small and large quadrupole magnets. The quadrupoles have lower temperature differentials because the water cooled tubes are better uniformly distributed. A small computer program was used with variable parameters to fit the magnet geometry. The calculations discussed were done for the large dipole which is the most critical of all the magnets. The only available space for the water cooled tubes was at each side of the rectangular chamber. This magnet is about $5 \mathrm{~m}$ long and weighs $41270 \mathrm{~kg}$. Figure 2 shows the cross section of the vacuum chambers and the bakeout components. The ceramic insulation with the glass cloth cover is $6.7 \mathrm{~mm}$ thick with a thermal conductivity of $0.08 \mathrm{~W} / \mathrm{m}^{\circ} \mathrm{C}$. Steady state heat

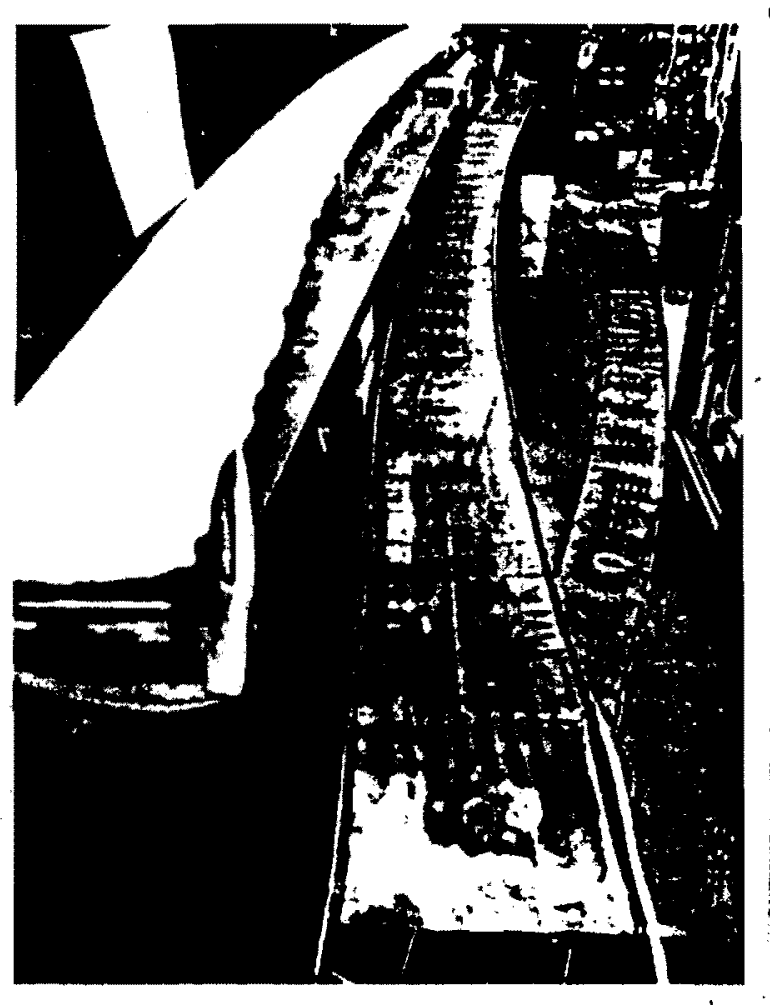

FIc. 7. Large dipole heating blanket and copper heat sinks. losses to keep the stainless steel chamber at $300^{\circ}$ is about 3.2 $\mathrm{k} W / \mathrm{m}^{2}$.

The copper shield intercepts about $53 \%$ of the heat and conducts it into the water tube. The temperature of the shield is $45^{\circ} \mathrm{C}$. The stcel laminations next to the copper sheet are assumed to have the same temperature. The heat that goes into the magnet steel is dissipated into two paths. About half goes into the magnet copper coil which is water cooled and the remaining is dissipated from the surface of the magnet into the air. The thermal conductance for the surface was $10 \mathrm{~W} / \mathrm{m}^{2}$ " $\mathrm{C}$. The calculated temperature of the magnet surface is about $38^{\circ} \mathrm{C}$. Water cooling is very important to reduce the heat dissipated into the tunnel enclosure. Between the heat shield and the coils, about $75 \%$ of the heat is removed by water.

Calculations for the quadrupole magnets were also done. Temperature distributions were a little lower than the dipole magnet. The steady heat losses were $3.8 \mathrm{~kW} / \mathrm{m}^{2}$ for the large quadrupole and $5.4 \mathrm{~kW} / \mathrm{m}^{2}$ for the small quadrupole magnet.

\section{TEST RESULTS}

Figure 7 shows a prototype vacuum chamber for the large dipole with the heating blanket and the copper heat sinks on the side. Four prototype heating blankets were tested. The data discussed was taken with the ISOPAD heating blanket which was chosen for best qualities of heat distribution, construction, and cost.

Figure 8 shows one of the large dipoles under measurement. The prototype bakeout tests were not made inside the magnet because of the work involved in opening and closing the half-cores. Instead, aluminum plates were clamped on the top and bottom of the copper heat sink to closely simulate the heat losses into the magnet. With $3.9 \mathrm{~kW} / \mathrm{m}^{2}$ of heating available from the blanket, temperat ure distribution on the surface of the chamber was recorded as shown on Fig. 9. One thermocouple was controlling the power. At $4.2 \mathrm{~min}$ intervals, the power was on $87 \%$ of the time.

The temperature at the surface of the copper heat shield

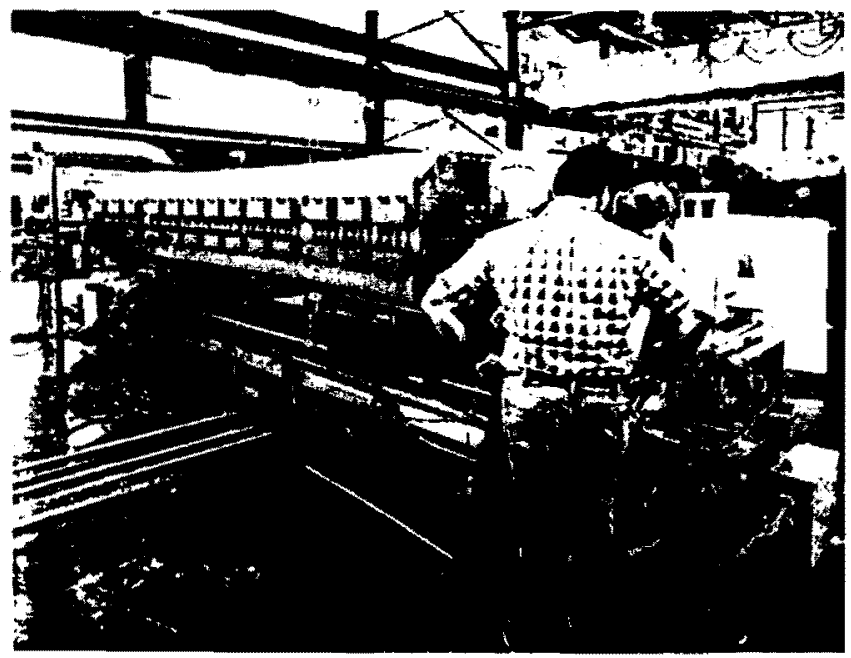

Fic. 8. Large dipole magnet. $: \because T$ 


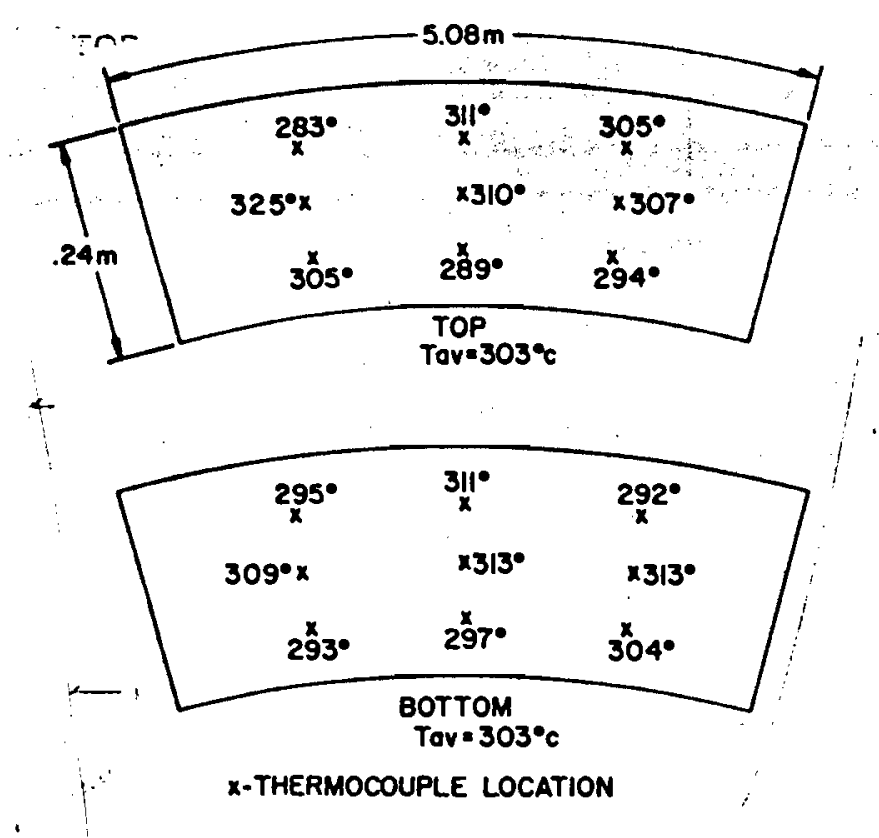

FIG. 9. Large dipole chamber measured temperature distribution. ,

averaged $64^{\circ} \mathrm{C}$. This was much higher than the calculated $45^{\circ} \mathrm{C}$ temperature. Without water cooling, the temperature of the copper went up to $97^{\circ} \mathrm{C}$. This showed the importance of the water cooled heat sink to remove the heat close to the source. With water cooling, the $80^{\circ} \mathrm{C}$ critical temperature of the epoxy was not reached. The tenperature of the aluminum surface next to the copper sheet was $47^{\circ} \mathrm{C}$. nuch lower than the shield. The theoretical assumption was not correct and one explanation is the unpredictable air tilm causing a thermal barrier between the Iwo surfaces. This thermal barrier, of course, will help in lowering the temperature of the laminations. The temperature of the aluminum plate without water cooling went up to $67^{\circ} \mathrm{C}$.

Temperature measurements on the quadrupole magnets will be made during the final assembly. The temperature on the copper heat sink is expected to be less than the one measured on the dipole because better distribution of the water tubes was possible.

\section{CONCLUSION}

A $300^{\circ} \mathrm{C}$ vacuum bakeout system was designed and tested. With only $7.5 \mathrm{~mm}$ average space available around the vacuum chamber, a temperature of $64^{\circ} \mathrm{C}$ was measured next to the magnet components. This was made possible using a water cooled copper heat shield covering the heating blanket. Additional thermal protection is evident from the thin air film between the copper shield and the magnet components.

The basic bakeout systen design is satisfactory for the dipole and quadrupole magnets.

'J. A. Satti, Fermilab Specification No. 2214-ES-187698, 5 June 1984. 